\title{
Study on Characters of Rural Residential Buildings Based on the Investigation in Shaanxi, Guangxi and Jiangsu in China
}

\author{
Li Zhihong ${ }^{1,}$, Huang Xianming ${ }^{1}$, Yuan Duo ${ }^{1}$, and Ma Yingying ${ }^{1}$ \\ ${ }^{1}$ Architectural Design and Research Institute of Tsinghua University Co., LTD, Chaoyang District, China
}

\begin{abstract}
This paper is supported by the national key R\&D program（2018YFD1100205） of China during the 13th Five-Year Plan "Research on the Construction Technology System of Green Livable Rural Residential Buildings". This paper is focused on the characteristics of rural residential buildings form, functional space and villagers' demands of buildings based on different regions, climate and economic performance. The research is processed in the field with spot plotting and questionnaire survey including interviews about the rural residential buildings in Luonan County of Shaanxi, Longan County of Guangxi and Wujiang District of Jiangsu. According to the statistical results, there is a contrastive analysis of rural residential buildings in time and space, and then the characteristics, influencing factors, modular spatial type of residential buildings have been teased out. Meanwhile it refines the development trends of rural residential buildings eventually combined with the demands of villagers.
\end{abstract}

\section{Introduction}

To build the beautiful village, improve human settlement environment in village and comprehensively build a welloff society is one of the mission goals in China at this stage. With China's economy stepping into a new normal, a new look of urban and rural construction has been gradually opened in the vast rural areas and it is accelerating the transformation from the urban-centered to the coordinative development of urban and rural areas. The 2014 National New Urbanization Plan (2014-2020) clearly puts forward that the basic principles of urbanization construction, which are people-oriented, overall planning of urban and rural areas, optimizing the layout, an intensive and efficient development [1]. The government work report of the State Council in 2019 states that rural construction should be compared with the goal of building a moderately prosperous society in all respects, and effectively promoting the poverty alleviation and rural revitalization [2].The green and livable rural residential buildings have become the focus of attention along with the deepening and acceleration of new countryside's development. However, according to the research about the current state in the wide rural areas of China, the development has many negative influences such as lacking unified planning and design, chaotic layout of buildings, a serious waste of land resources and so on[3]. Also there are many of the problems in construction of residential buildings, such as unplanned and crude construction, low quality, less secure and lower quality of indoor environment caused by the traditional construction model in rural which is normally grouped by the house owner, relatives and friends or temporary team composed by villagers without professional training. But from another angle, it fits actual demands of villagers for production and living greatly as the villagers are taking part in the whole process of construction. Therefore, it has realistic needs for the research of technology on green and livable rural residential building construction based on the studies of current situation, spatial characteristics and demands for buildings in rural areas.

\section{Research path}

This paper conducts literature studies, field observation and interviews to understand the external environment factors such as the status quo of rural planning, economic development, main source of income, rural policy of the government and the cultural customs. Meanwhile, by questionnaire survey and mapping, the characters of functional space, construction materials, technology and demands of villagers for the houses are summarized. On the basis of sorting out the relationship between external environment factors and characters of rural residential construction, this paper carries out initial exploration in internal mechanism of evolution of rural residential buildings and summarizes characters of green and livable rural residential buildings in the future combining with the target of green, livable and demands of villagers.

\section{Research overview}

In order to comprehensively understand the current situation and demands of rural residential buildings in different regions and periods, the research team carried out field research in Luonan County of Shaanxi Province, Longan County of Guangxi Province and Wujiang District of Jiangsu Province. The layout of rural areas investigated is shown in Fig. 1. The principle and method of survery is

*Corresponding author: lizhihong0217@foxmail.com 
to select the typical buildings of village settlement to be representative. Eventually there are 196 questionnaires and 78 drawings completed.

The social and economic background research of three regions mentioned above is summarized in Table 1 . In terms of regional industries, the local industries in Luonan,
Longan are mainly traditional cultivation and breeding while Wujiang is dominated by manufacturing and new industries. In terms of infrastructure, Wujiang district sets up a relative perfect infrastructure and Luonan and Longan need to improve water supply and drainage system.

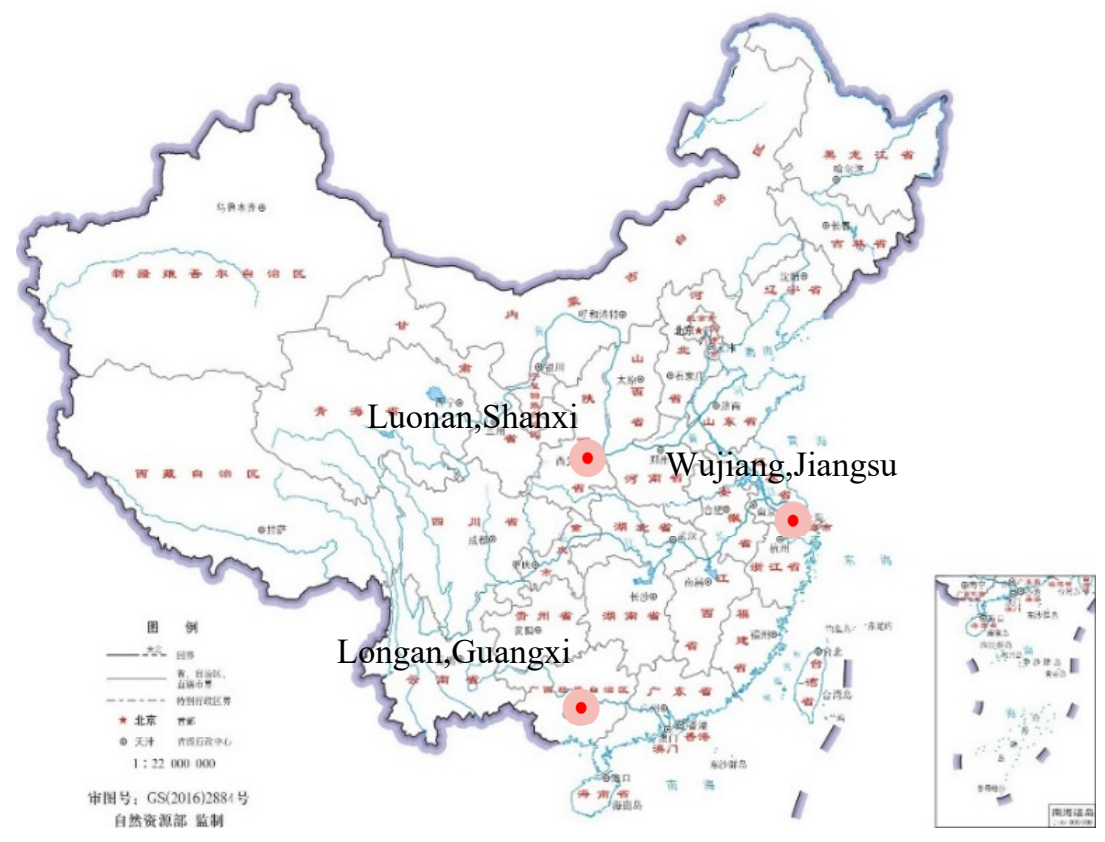

Fig. 1. Distribution map of survey villages
- Luonan Shaanxi is located in the hill area of loess plateau of northwest China and has an arid and semi-arid continental monsoon climate. This region is poor in vegetation cover and water resources.

- Wujiang Jiangsu locates at the east coast of China, mild climate, four seasons, with plenty of rainfall. The landscape is mostly flat.

- Longan Guangxi is located in the southern mountainous hilly region of China. The climate belongs to sub-tropical humid monsoon climate with hot and rainy, short winter.

Table 1. Social and economic background survey

\begin{tabular}{|c|c|c|c|}
\hline & Luonan Shaanxi & Longan Guangxi & Wujiang Jiangsu \\
\hline $\begin{array}{l}\text { Major industries } \\
\text { in the region }\end{array}$ & Faiming and Breeding & Faiming and Breeding & Manufacturing and new industries \\
\hline $\begin{array}{l}\text { Main types of family } \\
\text { economy }\end{array}$ & $\begin{array}{l}\text { Farmer, Migrant work, Half } \\
\text { labour and half pessant }\end{array}$ & $\begin{array}{l}\text { Farmer, Migrant work, } \\
\text { Half labour and half pessant }\end{array}$ & $\begin{array}{l}\text { Local job, self-employed, Half labour } \\
\text { and half pessant,Farmer }\end{array}$ \\
\hline Infrastructure & $\begin{array}{l}\text { Roads, electricity, } \\
\text { communications and public } \\
\text { services are relatively } \\
\text { complete, inadequate water } \\
\text { supply and drainage facilities }\end{array}$ & $\begin{array}{l}\text { Roads, electricity, } \\
\text { communications and public } \\
\text { services are relatively complete, } \\
\text { inadequate water supply and } \\
\text { drainage facilities }\end{array}$ & $\begin{array}{l}\text { Roads, water supply and sewage, } \\
\text { electricity, communications, public } \\
\text { services and other aspects are very } \\
\text { perfect }\end{array}$ \\
\hline
\end{tabular}

Fig. 2 shows the gross domestic product and disposable income per capitat of local rural residents in Luonan, Longan and Wujiang in 2017. It is apparent form the chart that the GDP and PDI of Wujiang are much higher than that of Luonan and Longan, and Wujiang is at a higher level of rural economic development in China. The types 
of rural family income are shown in Fig. 3. The ratios of rural labor migration family are respectively $33 \%$ and $21 \%$ of the households surveyed in Luonan and Longan, and the hollowing and aging phenomenons are observed in these areas during the survey. In Wujiang, only $4 \%$ of the households surveyed are rural labor migration family, and most of them are locality workers or self-employed. It is obviously that the urbanization level of Wujiang is much higher than Luonan and Longan.

According to the analysis above, Luonan and Longan have the typical characteristics of traditional rural, while Wujiang is the new-type developed rural at the present stage in China.

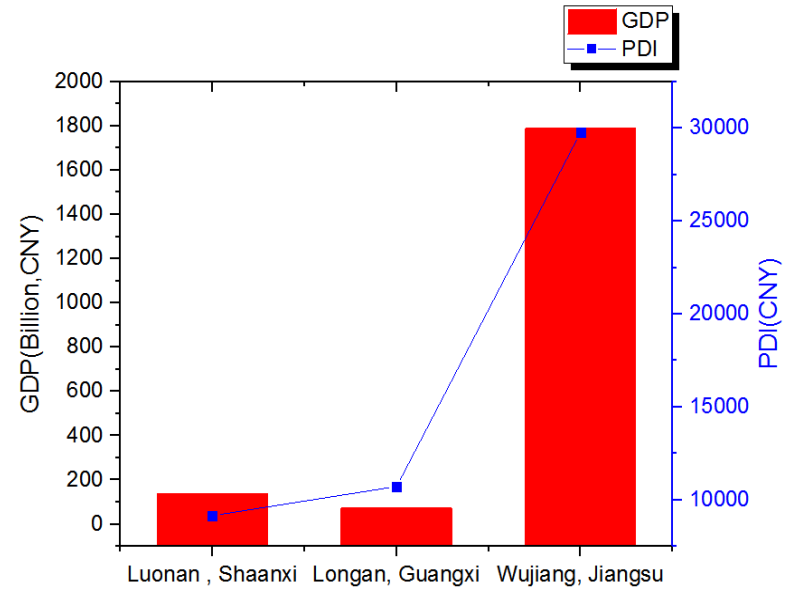

Fig. 2. The personal disposable income and gross domestic product in 2017

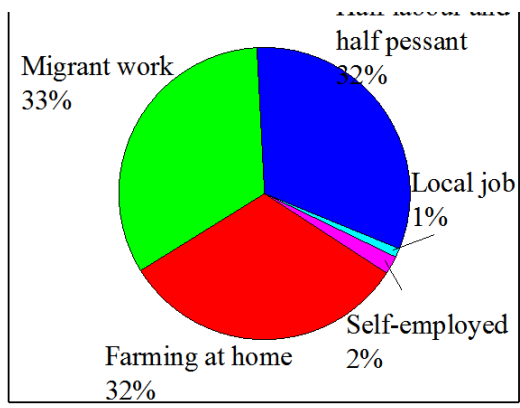

Luonan, Shaanxi

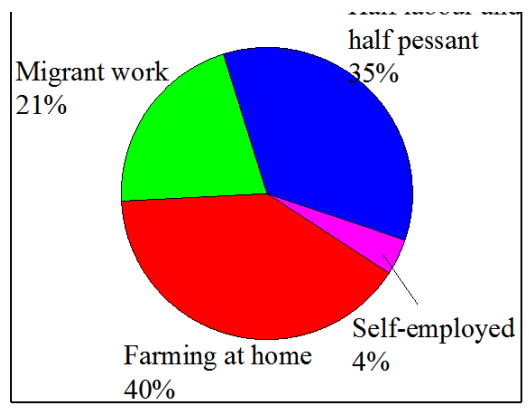

Longan, Guangxi

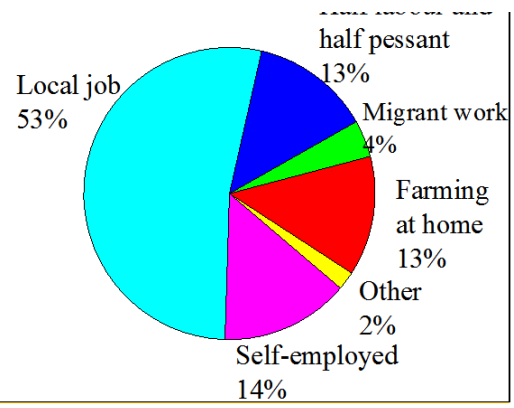

Wujiang, Jiangsu

Fig. 3. Types of rural family income

\section{Analysis on the evolution of rural residential construction}

Since the reform and opening up 40 years, the rural development consists five stages in China [4]. At each stage, the national rural policies have greatly promoted the rural economic level. The economic development brings about the changes in technology, awareness, people living styles and other aspects. And meanwhile, times features are responsed in the form of buildings accordingly. The characteristics of residential buildings in this survey are summarized and shown in Table 2 and Fig. 4.

Table 2. The investigation of building form in rural areas

\begin{tabular}{|c|c|c|c|c|c|c|c|}
\hline & \multicolumn{2}{|l|}{ Period } & $\begin{array}{c}\text { The 1970s and } \\
\text { before }\end{array}$ & The 1980s & The $1990 \mathrm{~s}$ & $\begin{array}{c}\text { From } 2000 \text { to } \\
2009\end{array}$ & Since 2010 \\
\hline \multirow{6}{*}{$\begin{array}{l}\text { Luonan, } \\
\text { Shaanxi }\end{array}$} & \multicolumn{2}{|c|}{ Sample photos } & & & & & \\
\hline & \multicolumn{2}{|c|}{$\begin{array}{l}\text { Residential units } \\
\text { (94 in total) }\end{array}$} & 7 units & 12 units & 11 units & 20 units & 44 units \\
\hline & \multirow{2}{*}{ Layer } & Single & $100 \%$ & $100 \%$ & $55 \%$ & $35 \%$ & $23 \%$ \\
\hline & & Multi & $0 \%$ & $0 \%$ & $45 \%$ & $65 \%$ & $77 \%$ \\
\hline & \multirow{2}{*}{ Shapes of Roof } & Flat & $29 \%$ & $25 \%$ & $45 \%$ & $50 \%$ & $50 \%$ \\
\hline & & Pitched & $71 \%$ & $75 \%$ & $55 \%$ & $50 \%$ & $50 \%$ \\
\hline \multirow{2}{*}{$\begin{array}{l}\text { Longan, } \\
\text { Guangxi }\end{array}$} & \multicolumn{2}{|c|}{ Sample photos } & & & & & \\
\hline & \multicolumn{2}{|c|}{ Residential units } & 7 units & 5 units & 12 units & 22 units & 11 units \\
\hline
\end{tabular}




\begin{tabular}{|c|c|c|c|c|c|c|c|}
\hline & \multicolumn{2}{|c|}{ (57 in total) } & & & & & \\
\hline & \multirow{2}{*}{ Layer } & Single & $100 \%$ & $40 \%$ & $8 \%$ & $18 \%$ & $27 \%$ \\
\hline & & Multi & $0 \%$ & $60 \%$ & $92 \%$ & $82 \%$ & $73 \%$ \\
\hline & \multirow{2}{*}{ Shapes of Roof } & Flat & $100 \%$ & $100 \%$ & $100 \%$ & $86 \%$ & $82 \%$ \\
\hline & & Pitched & $0 \%$ & $0 \%$ & $0 \%$ & $14 \%$ & $18 \%$ \\
\hline \multirow{6}{*}{$\begin{array}{l}\text { Wujiang, } \\
\text { Jiangsu }\end{array}$} & \multicolumn{2}{|c|}{ Sample photos } & & & & 1 & \\
\hline & \multicolumn{2}{|c|}{$\begin{array}{l}\text { Residential units } \\
\text { (45 in total) }\end{array}$} & 2 units & 2 units & 24 units & 7 units & 10 units \\
\hline & \multirow{2}{*}{ Layer } & Single & $50 \%$ & $0 \%$ & $0 \%$ & $0 \%$ & $0 \%$ \\
\hline & & Multi & $50 \%$ & $100 \%$ & $100 \%$ & $100 \%$ & $100 \%$ \\
\hline & \multirow{2}{*}{ Shapes of Roof } & Flat & $50 \%$ & $0 \%$ & $29 \%$ & $14 \%$ & $9 \%$ \\
\hline & & Pitched & $50 \%$ & $100 \%$ & $71 \%$ & $86 \%$ & $91 \%$ \\
\hline
\end{tabular}

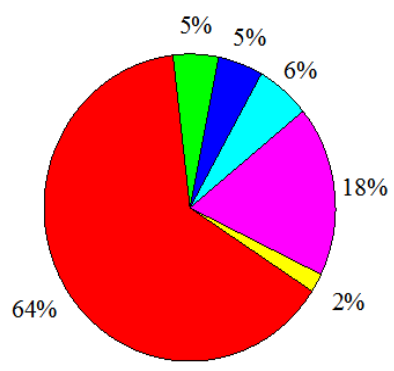

Luonan,Shaanxi

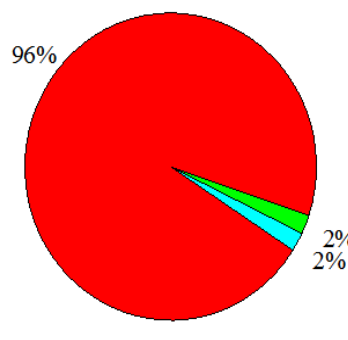

Longan, Guangxi

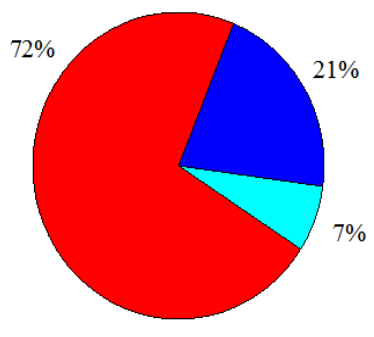

Wujiang,Jiangsu
Brick and concrete structure

Reinforced concrete shear wall structure Reinforced concrete frame structure Brick-timber structure

Rammed earth and timber frame structure Other

(a) Structure type

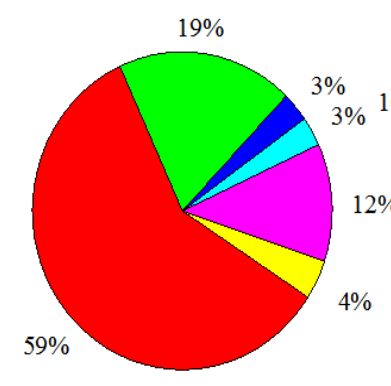

Luonan,Shaanxi

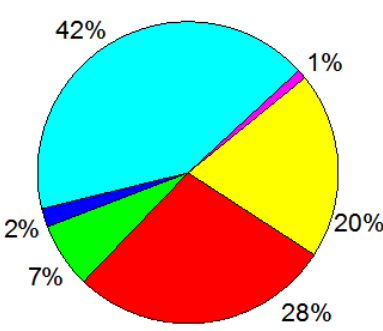

Luonan,Shaanxi
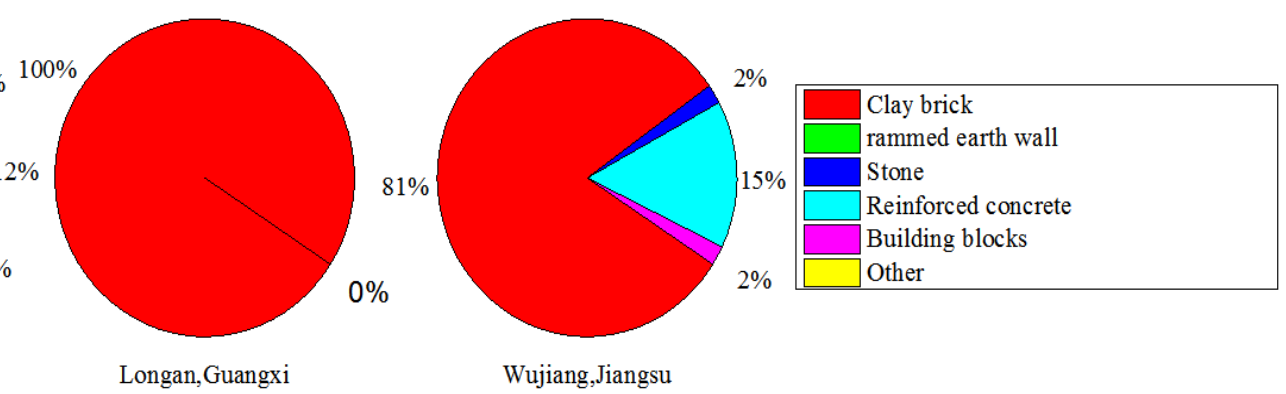

(b) Exterior wall type

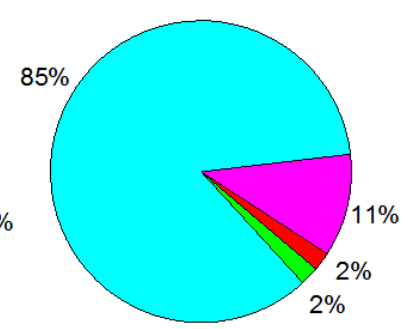

Longan,Guangxi

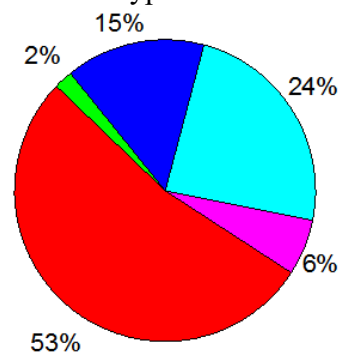

Wujiang,Jiangsu
Timber roof truss and tile

Steel roof truss and tile

Reinforced concrete and tile

Cast-in-situ reinforcement concrete

Precast concrete plank

Other

(c) Roof type

Fig. 4. Form characteristics of residential buildings surveyed 


\subsection{Building form}

The 1970s and before which is just before the reform and opening up of china, the overall social environment is relatively closed and the level of economy, technology is generally low in rural. The construction mainly continues the traditional mode and technology. In this stage, the differences of buildings in the surveyed areas are generally small, Single-storey, sloping roof with timber roof truss and tile. During the investigation, it is obvious that at this stage, the rural residential buildings are generally with a lower wall, smaller window and door holes and a raw shell appearance without the cladding. However, there are still some obvious characters of buildings which are restricted by the climate and natural resource in different regions. The features of vernacular buildings are presented such as rammed earth and timer frame structure in Shaanxi, stone and wood structure in Guangxi, brick and wood structure in Jiangsu. Regional climate and traditional construction techniques are fully reflected in the residential construction at this stage.

In the 1980s and 1990s, with the reform and opening up, the productivity and thoughts have been greatly liberated. Living standards of villagers are improved and the development of buildings construction begins a new stage. Reinforced concrete and some multilayer buildings in rural have appeared in developed and less developed regions at this stage. In the regions surveyed, most of the multi-storey houses are two-storey with brick and concrete structure. In term of roof construction, the flat roof is widely used in Longan due to waterproofing technology, convenient construction and small construction difficulty. Though there are some buildings with flat roof in Luonan and Wujiang, the pitched roof is still dominant which is affected by the construction experience, local culture customs and climates. In this stage, clay bricks are commonly employed as the exterior walls in rural. With the strength of exterior walls improved, the height of wall is higher about 3 meters or more and the window and door holes are larger than before. At the same time, influenced by urban social, economic and cultural, the materials used on facades become various, such as tiles, exposed concrete, paint, clay brick and so on. But in Guangxi, the facades are greatly influenced by humid climate and the surface of the facade is generally exposed without any decorations to avoid falling out and stained due to the humid weather.

Since 2000, Along with the rapidly development of reform and opening up, the implementation of new rural construction and revitalization strategy, the rural human settlements have been greatly improved. In recent years, the rural policy has become one of the main factors affecting the form of building in rural areas. For example, new houses are required to be exploited on former homestead in some villages of Luonan, and in some areas of Longan, only one-storey houses are allowed for new buildings. In Wujiang, with the implementation of policies such as "beautiful village" "characteristic and idyllic village" and "livable villages", the styles and features of new buildings have been controlled, and the differences have been shrunk gradually in a certain region. Due to the further tightening of rural homestead policy, the vertical expansion of rural residential buildings has been intensified and embodies in this survey. Rural residential buildings surveyed are generally 2-3 floor in this period. Brick and concrete is the major structural system, and there has a certain proportion of buildings with reinforced concrete frame structure. Most of them are mainly distributed in economically and technologically developed areas as the construction cost of concrete frame structure is relatively high. In Wujiang, the proportion of the residential buildings with frame concrete structure has reached $21 \%$ of the samples. With the concrete construction technology promoted and applied in rural areas, some of buildings constructed in recent years also have adopted concrete frame structure in Luonan. The roof form of residential buildings in Luonan shows that the ratios of flat roof and slop roof are close. Flat roof is still the major style of rural buildings in Longan, while slope roof is the main form in Wujiang affected by the policy, construction experience, and local culture customs. The proportion of wall with exterior finish is increased in the survey regions and the exterior finish is mainly cement mortar, coating and tiles.

Throughout the evolution of rural residential buildings, the form of buildings is mainly affected by economic, resources and construction technology level in the early stage, while at the present stage, it is mainly affected by policies and consciousness of builders. From the past to the present, most of rural residential buildings in china are still mainly self-built, the builders are grouped by blood relationship, neighbourhood or local craftsmen, so it is greatly influenced by the construction technology and the consciousness of builders. Information and technology are developed slowly in the past, therefore, the residential form has been fully continued in traditional rural areas. However, in developed villages, the development of Information and technology are relatively fast and building construction has begun to trend to the urbanization mode with professional design and construction team. The buildings are usually with higher construction level and variety of forms but at the same time, the regional characteristics and traditional culture are lacking seriously. With the process of urban-rural integration and rural construction in China, a great deal of information and technology are imported into vast rural areas. It will be further shrinking the distance of residential buildings form between traditional and newly developed rural based on the development of infrastructure and logistics in rural areas. This phenomenon has been reflected in this survey, as shown in Fig. 5. 


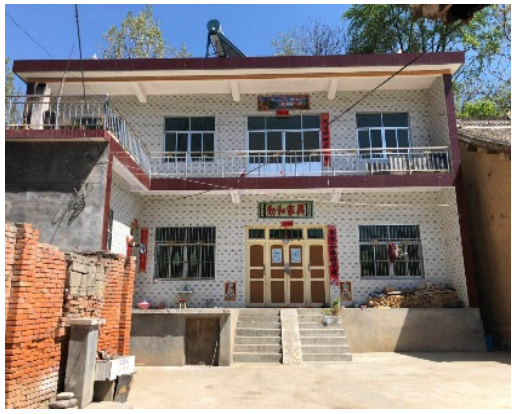

Case in Luonan, Shaanxi

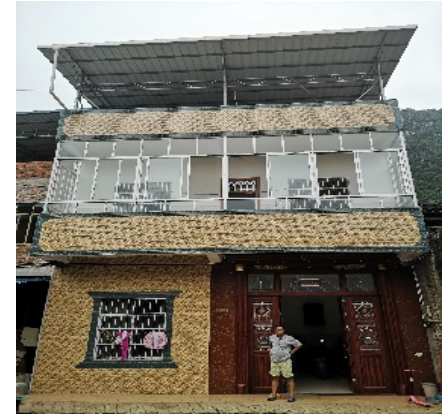

Case in Longan, Guangxi

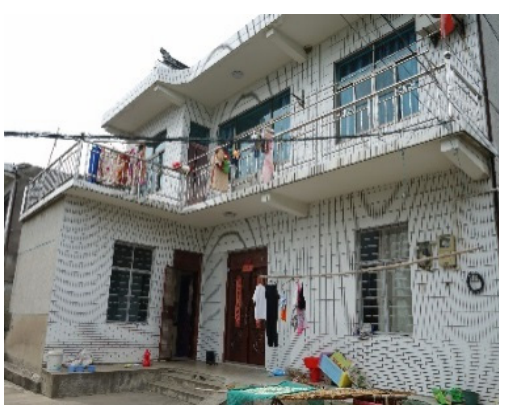

Case in Wujiang, Jiangsu

Fig. 5. Appearance of rural residential surveyed

\subsection{Functional space}

78 buildings were mapped randomly in the surveyed residential buildings during this survey. The plane of these residential buildings can be generalized into 4 types- L type, $U$ type, flat plate and others and the statistical is shown in Fig. 6. It shows the main type of survey plane in Luonan is L type. Normally, the L type is composed by principal room and subsidiary space and it forms a courtyard as a semi enclosed space. While the principal forms of plane in Longan is flat plate which is largely affected by topography and generally without courtyard. Flat plate and L type are the main types in Wujiang and there is usually an enclosed courtyard formed by wall and/or fences.

The traditional residential buildings in China is threebay house with a hall and two bedroom or accessory spaces. Functional space of residential buildings surveyed mainly continues the traditional model with local evolution according to the analysis of residential functional space surveyed. The transformation regulation of the functional space is summarized and present in Table 3 .

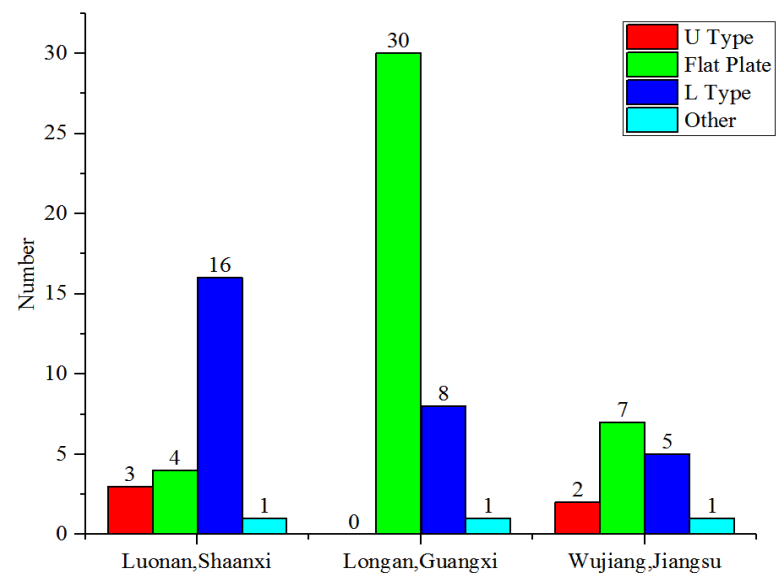

Fig. 6. The statistical of residential plane type

Table 3. Types of functional space layout

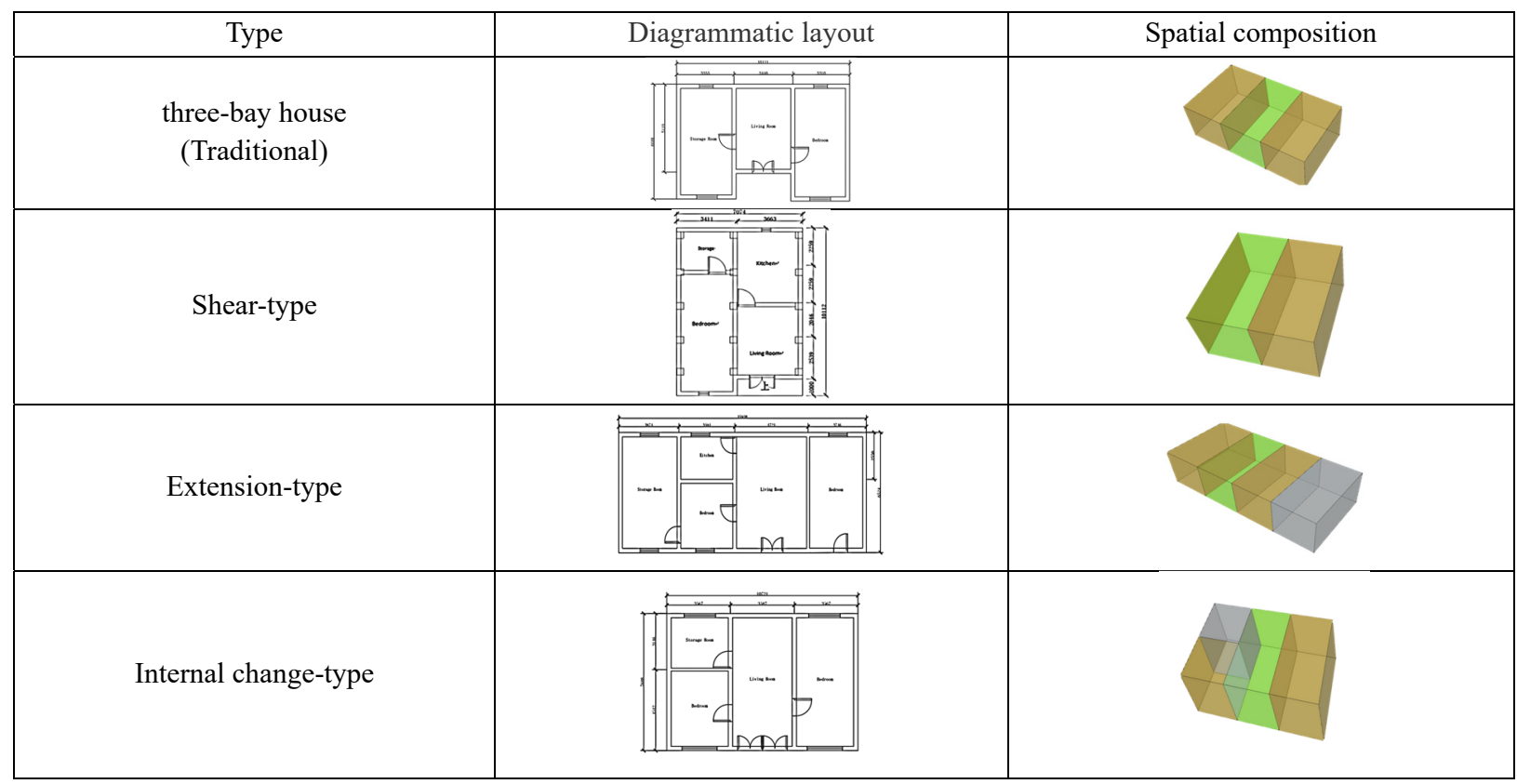




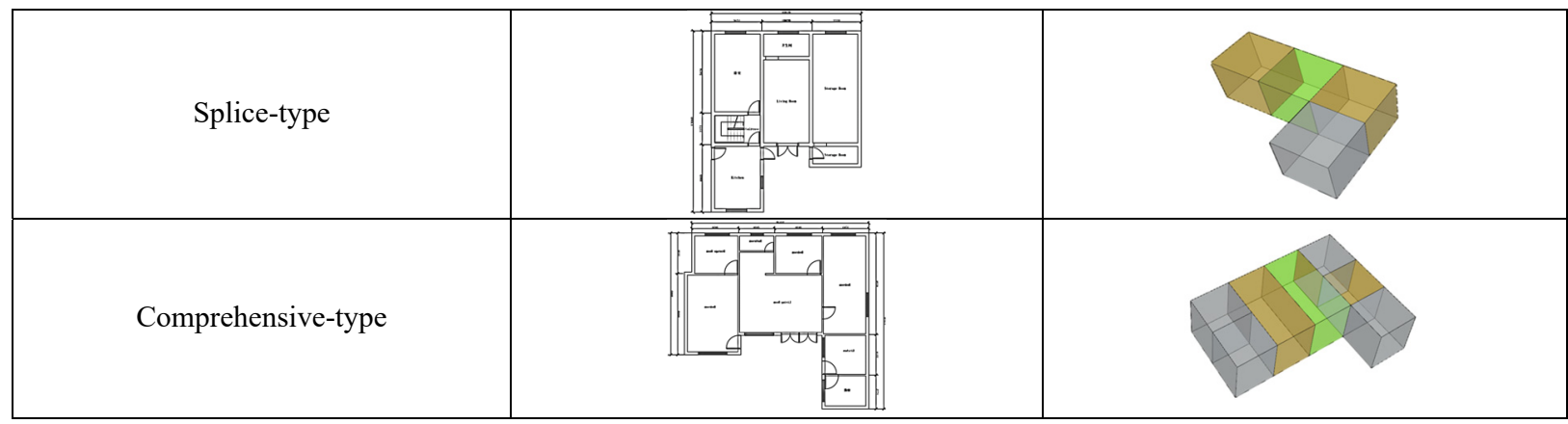

- Shear-type. This type is simplified to two bay or a small bay with large depth by the traditional type. It is normally affected by topography. Generally the large depth is divided vertically, and it is more common in Guangxi region.

- Extension-type. Generally this type extends horizontally on a relatively flat and open site, and the extension can be unilateral or bilateral based on traditional type. Usually, the three-bay house is mainly as the core area of daily life and the extension zone is set as the secondary bedroom or ancillary space such as storage ,kitchen, staircase and so on.

- Internal change-type. Interior space is divided and changed on the basis of traditional type. This type is a common spatial type in samples and it is compatible with the rural residential design approaches which is from big to small [5]. The overall space is divided into several small and suitable spaces to enable the functional spaces to be variety.

- Splice-type. L or U-shaped plane is formed by connecting ancillary space to traditional space type and such semi enclosed or enclosed space form is advantage in resisting adversary impacts of the external environment. This space type is common in Luonan region during the survey and the attached ancillary space is usually as kitchen, staircase or bedroom with kitchen.

- Comprehensive-type. It is combined freely with the space types above. This space type shows that the stronger adaptability of complex environment and diversified demand. A large number of rural residential buildings adopt this space type in the survey.

The functional space of rural residential buildings features modularization obviously according to the summarized and classified space layout. Bedroom and living room are the fundamental units of residential functional spaces, while other Spaces are set up based on the basic units. So the spatial scale of fundamental unit investigated has been studied and shown in Fig. 7 and Fig. 8.

It is shown in Fig. 7 that there is about $80 \%$ of the surveying and mapping bedroom samples which area is centralized to $10-25 \mathrm{~m}^{2}$, and the bedroom samples within $10-15 \mathrm{~m}^{2}$ account for a relatively large proportion about $43 \%$. The spatial scale characteristics of bedroom samples have been analysed further by the temporal and spatial as shown in Fig.9.

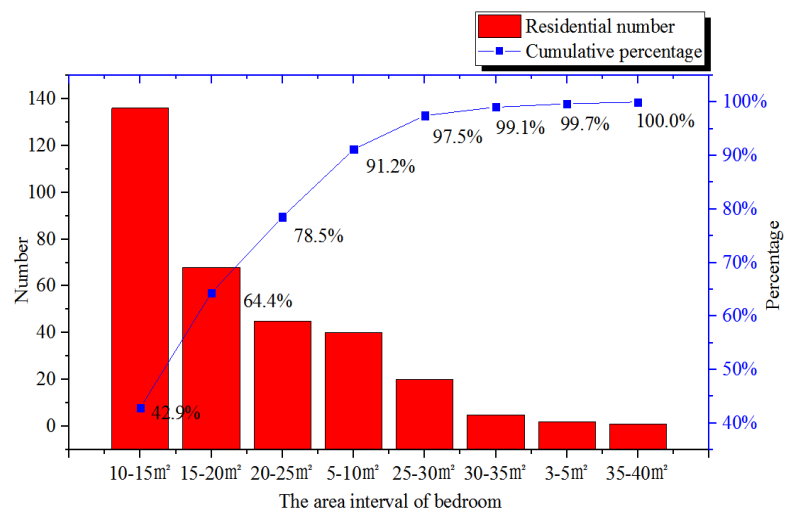

Fig. 7. Distribution of the bedroom area statistics

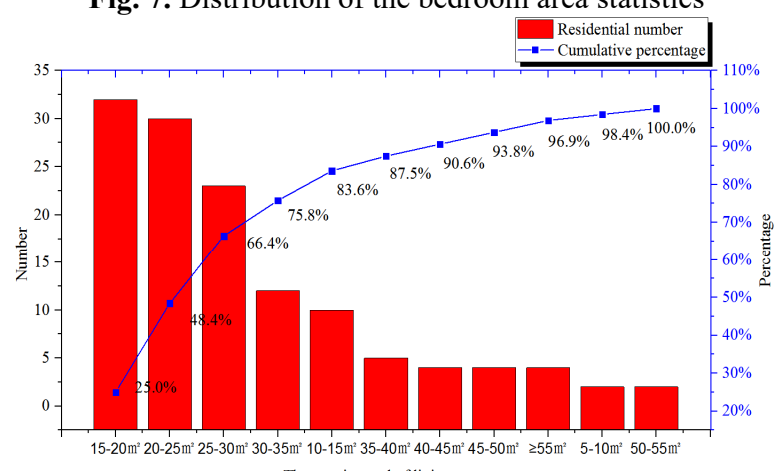

The area interval of living room

Fig. 8. Distribution of the living room area statistics

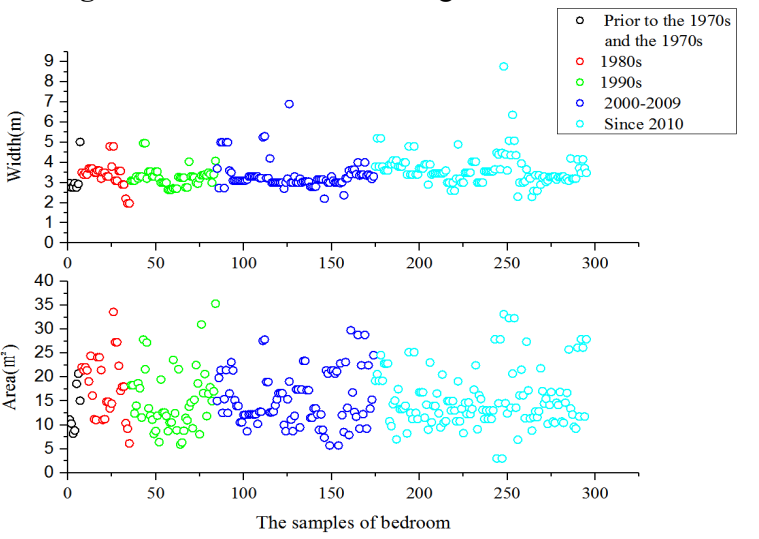

Fig. 9(a). Statistical analysis based on time 


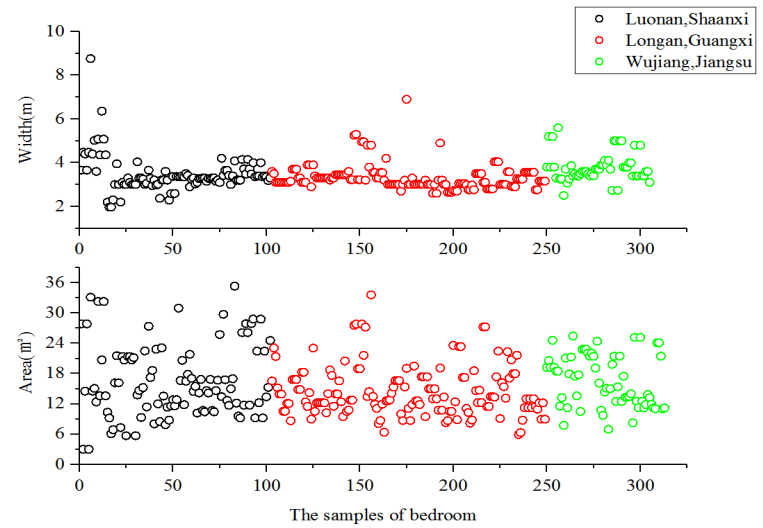

Fig. 9(b). Statistical analysis based on regions

The area of bedrooms is centralized to $10-25 \mathrm{~m}^{2}$ and the width focus on 3-4 $\mathrm{m}$ in various periods without obvious variation trend analysed from the time angle. From the perspective of regions, the area of bedroom samples in different regions is evenly distributed in 5-30 $\mathrm{m}^{2}$, and the distribution of width is basically 3-4 m consistent with each other. Although the width is very concentrated in Luonan, the area has a higher dispersed degree. It reflects that the depth is discrete and to a large extent is due to some of the bedrooms are mixed with kitchen in Luonan.

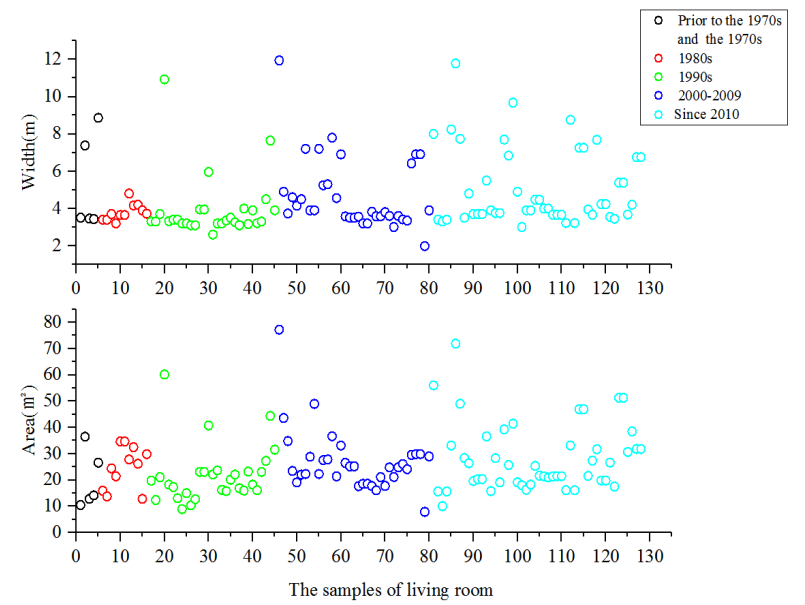

Fig. 10(a). Statistical analysis based on time

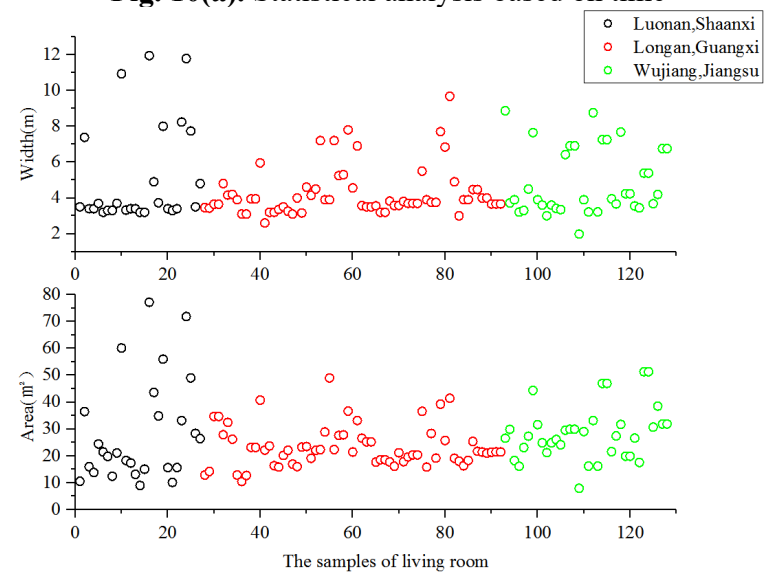

Fig. 10(b). Statistical analysis based on regions

$80 \%$ of the living room samples are concentrated in 15-35 $\mathrm{m}^{2}$ and the samples within 15-20 $\mathrm{m}^{2}$ account for a large proportion about $25 \%$ as shown in Fig. 8. According to Fig. 10, the area distribution of living room samples has no significant changes over time too. The width distribute of samples is generally centralized to 3-4 $\mathrm{m}$ in each period while the proportion of samples with a width larger than 6 $\mathrm{m}$ has been increased since 2000 due to the development of construction technique and building materials. From the regional perspective, the area of samples is mainly concentrated in 15-20 $\mathrm{m}^{2}$ in Luonan, 20-25 $\mathrm{m}^{2}$ in Longan and 25-30 $\mathrm{m}^{2}$ in Wujiang. The width distribution of samples is generally consistent in all regions.

The spatial scale of residential core units surveyed in different regions basically have a constant modulus according to the analysis results from the different temporal and spatial. And most of it has due to the continuation of the traditional residential modulus and the people are already used to this spatial scale in their daily.

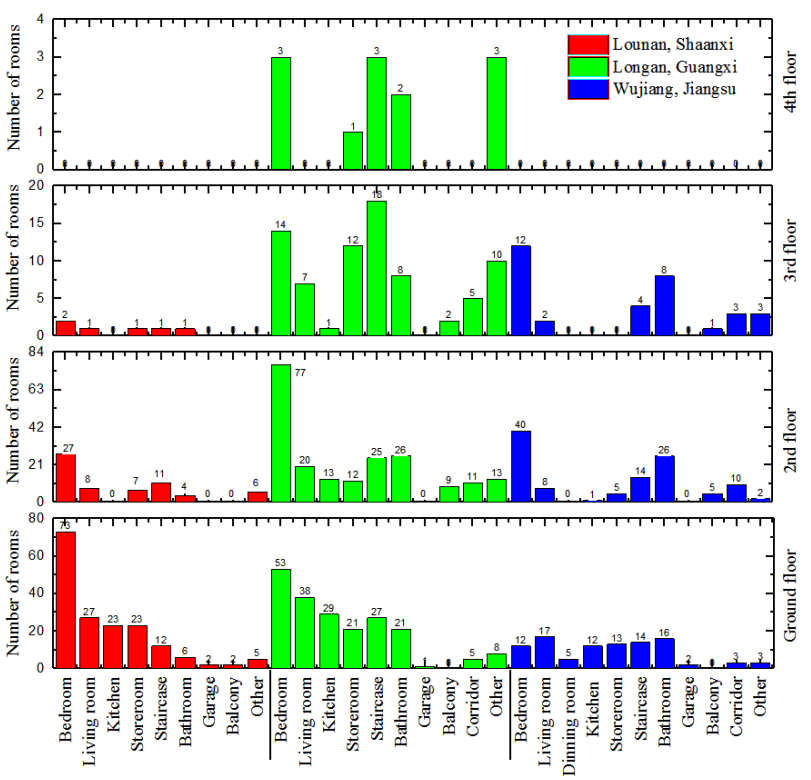

Fig. 11. The spatial layout of residential

The functional layout of residential surveyed is shown in Fig. 11. Most of the main space for activities is located on the ground floor in Luonan region and most of the villagers have a courtyard outside for leisure and communication, and generally the toilet is set independently in the courtyard. So it is more convenient for daily life and communication with neighbors to set the main space for activities on the ground floor. The main activities space of buildings in Longan and Wujiang is located on 2nd or above. The main reason is that there is normally no courtyard in rural residential in Guangxi or the size of courtyard limited and personal privacy in Jiangsu. Another reason is the climatic which major characteristics of Guangxi and Jiangsu is torridity and raininess and living above the ground floor can avoid moisture intrusion. Therefore, the daily life for villagers of those regions are mainly indoors and most of the residential buildings surveyed are set two or more living room interior. For most of villagers, the daily living activities such as accommodation and communication are on the 2nd floor and the main function of space on the ground floor is served as reception for guests, dining room, 
and storage for bicycle or electrical vehicle in Longan and Wujiang. The function layout of residential buildings surveyed in Wujiang is further improved and refined for the division of space is getting closer to urban house such as independent dinning space.

\section{Demands analysis}

The demands of the residential form and performance are investigated and the results are shown in Fig. 12 and Fig. 13. Single-family residential with 2-3 layers about 100$200 \mathrm{~m}^{2}$ is the most popular and it accounts for a large proportion in three different regions with various economic performance, geographical location and policies according to Fig.12. This desired form of residential buildings is in conformity with the fact about land policy tightening and vertical development trend. Single-family with single-storey, which is traditional buildings in rural, is also popular and second only to 2-3 layers. Some of the villagers preferred to remain the same because they have already used to the way of life during the interviewer.

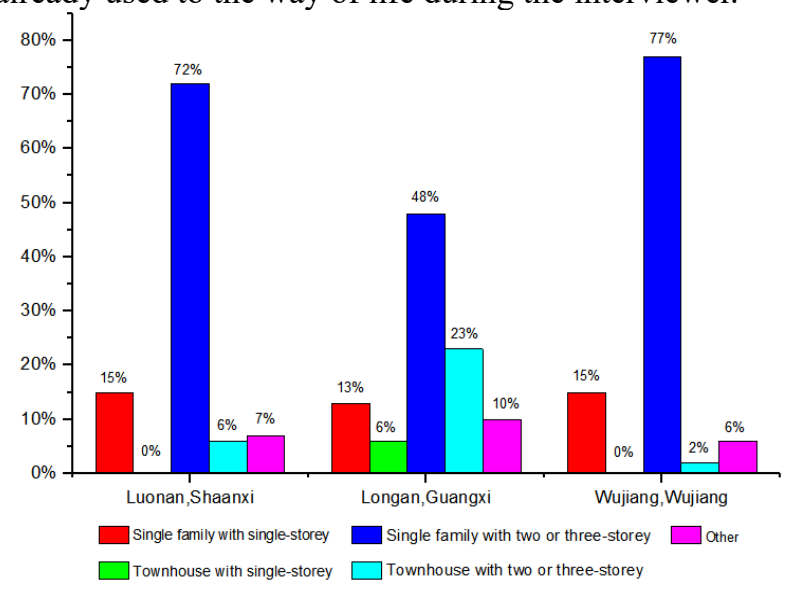

Fig. 12. The statistical demand for residential forms

The residential performance demands focused on are not identical in three region shown in Fig. 13. Due to the climate and social circumstances. It is mainly focused on area, orientation, sectorization, security and function requirement in Luonan. Ventilation and lighting, water and moisture resistance, orientation, comfortable environment and sectorization are more concerned in Longan. In Wujiang, ventilation and lighting, green, water and moisture resistance, function requirement and comfortable environment are mainly focused on. The concern to indoor environmental quality is obviously in this investigation such as orientation, ventilation and lighting, sectorization, water and moisture resistance and so on. Accordingly, continually improving indoor environment quality of rural residential buildings is one of the most important task at present and in the future.

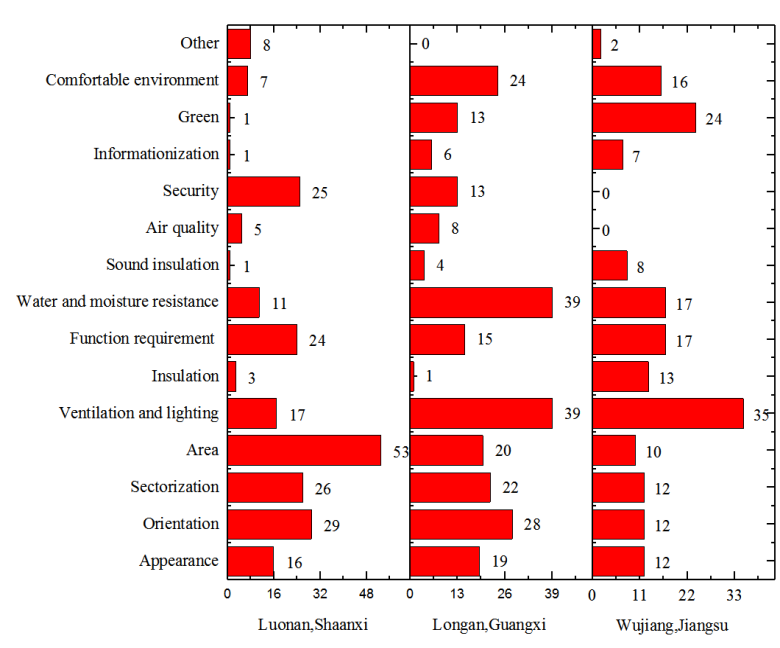

Fig. 13. The statistical demand for residential performance

\section{Conclusion}

The characters of rural residential buildings can be summarized as following based on analysis of the preceding context.

- The differences of residential construction in different phases are due to a variety of factors constraints at that time. Currently, the unbalanced development of construction techniques and engineer's working experience are major contributors to the differences in vast rural areas of China. With the development of urbanization and the spread of technology, the differences between city and countryside, traditional and new form of rural tend to be slightly while the impact of region factor, culture and policies are still not ignorable.

- Rural residential buildings surveyed in China have a modular structure. The functional space has been concluded to 5 types; the traditional type, shear-type, extension-type, internal change-type, splice-type and comprehensive-type. The spatial scale of residential basic unit is generally consistent in different phases and regions, and most of it has to do with the continuation of the traditional residential modulus and the people are already used to this spatial scale in their daily.

- Based on the present situation, land policies and villagers' demands of rural residential, single-family residential with 2-3 layers is one of the most popular types at this stage as well as the future development trends of rural.

- The functional division of rural residential tends to urbanization and be refined. The environment quality indoor of rural residential has become one of the focuses in the rural residential construction at present and in the future.

\section{References}

1. The national plan for new urbanization (2014-2020). People Publishing House. (2014)

2. The Government Work Report 2019. http://www.gov.cn/premier/2019-03/16/ content _5374314.htm. (2019) 
3. L.Y. Liu, Y.H. Zhu, X.C. W. The problems and the strategies in the self-establish buildings in rural. Chin. Home, 02 (2014)

4. S.A. Huang. The gradual evolution and theoretical summary of China's rural development strategy in the past 40 years of reform and opening up. Econ. Res., volume 53, 12 (2018)

5. B.S. Jia. "From big to small" and "From small to big": two approach about the systematization of residential. Arch. J., (1992) 